\title{
Inhaltsverzeichnis
}

Verzeichnis der Bearbeiter der 6. Auflage $-\mathrm{V}$

Vorwort zur 6. Auflage - VII

Abkürzungsverzeichnis -XIII

Verzeichnis der abgekürzt zitierten Literatur — XXV

DRITTES BUCH

Handelsbücher

ERSTER ABSCHNITT

Vorschriften für alle Kaufleute

ERSTER UNTERABSCHNITT

Buchführung. Inventar - 1

Vorbemerkungen Vor $\S 238-1$

$\S 238$ Buchführungspflicht -15

$\S 239$ Führung der Handelsbücher -54

$\S 240$ Inventar -74

$\S 241$ Inventurvereinfachungsverfahren - 107

$\S 241$ a Befreiung von der Pflicht zur Buchführung und Erstellung eines Inventars — 129

ZWEITER UNTERABSCHNITT

Eröffnungsbilanz. Jahresabschluß 137

ERSTER TITEL

Allgemeine Vorschriften - 137

$\S 242$ Pflicht zur Aufstellung - 137

$\S 243$ Aufstellungsgrundsatz -162

$\S 244$ Sprache. Währungseinheit — 177

$\S 245$ Unterzeichnung - 184

ZWEITER TITEL

Ansatzvorschriften -194

$\S 246$ Vollständigkeit. Verrechnungsverbot -194

$\S 247$ Inhalt der Bilanz 235

$\S 248$ Bilanzierungsverbote und -wahlrechte - 255

$\S 249$ Rückstellungen -270

$\S 250$ Rechnungsabgrenzungsposten -298

$\S 251$ Haftungsverhältnisse -308

DRITTER TITEL

Bewertungsvorschriften -317

§ 252 Allgemeine Bewertungsgrundsätze - 317

$\S 253$ Zugangs- und Folgebewertung — 344

$\S 254$ Bildung von Bewertungseinheiten — 382

$\S 255$ Anschaffungs- und Herstellungskosten - 397

$\S 256$ Bewertungsvereinfachungsverfahren - 426

$\S 256$ a Währungsumrechnung -439 


\section{DRITTER UNTERABSCHNITT}

\section{Aufbewahrung und Vorlage -450}

$\S 257$ Aufbewahrung von Unterlagen. Aufbewahrungsfristen -450

$\S 258$ Vorlegung im Rechtsstreit — 476

$\S 259$ Auszug bei Vorlegung im Rechtsstreit - 488

$\S 260$ Vorlegung bei Auseinandersetzung — 492

$\S 261$ Vorlegung von Unterlagen auf Bild- oder Datenträgern — 495

\section{VIERTER UNTERABSCHNITT}

Landesrecht -502

$\S 262$ (aufgehoben) -502

$\S 263$ Vorbehalt landesrechtlicher Vorschriften -503

\section{ZWEITER ABSCHNITT}

Ergänzende Vorschriften für Kapitalgesellschaften (Aktiengesellschaften, Kommanditgesellschaften auf Aktien und Gesellschaften mit beschränkter Haftung) sowie bestimmte Personenhandelsgesellschaften -508

\section{ERSTER UNTERABSCHNITT}

Jahresabschluß der Kapitalgesellschaft und Lagebericht -508

ERSTER TITEL

Allgemeine Vorschriften -508

$\S 264$ Pflicht zur Aufstellung; Befreiung - 508

$\S 264 \mathrm{a}$ Anwendung auf bestimmte offene Handelsgesellschaften und Kommanditgesellschaften -551

$\S 264 \mathrm{~b}$ Befreiung der offenen Handelsgesellschaften und Kommanditgesellschaften im Sinne des § 264a von der Anwendung der Vorschriften dieses Abschnitts — 557

$\S 264 \mathrm{C}$ Besondere Bestimmungen für offene Handelsgesellschaften und Kommanditgesellschaften im Sinne des $\S 264 a-561$

$\S 264 d$ Kapitalmarktorientierte Kapitalgesellschaft — 574

$\S 265$ Allgemeine Grundsätze für die Gliederung — 576

ZWEITER TITEL

Bilanz -586

$\S 266$ Gliederung der Bilanz -586

$\S 267$ Umschreibung der Größenklassen - 610

$\S 267$ a Kleinstkapitalgesellschaften -619

$\S 268$ Vorschriften zu einzelnen Posten der Bilanz. Bilanzvermerke - 624

$\S 269$ (aufgehoben) - 640

$\S 270$ Bildung bestimmter Posten - 641

$\S 271$ Beteiligungen. Verbundene Unternehmen — 643

$\S 272$ Eigenkapital -656

$\S 273$ (aufgehoben) -685

$\S 274$ Latente Steuern — 686

§ 274a Größenabhängige Erleichterungen — 706

DRITTER TITEL

Gewinn- und Verlustrechnung - 709

$\S 275$ Gliederung — 709

$\S 276$ Größenabhängige Erleichterungen — 739

$\S 277$ Vorschriften zu einzelnen Posten der Gewinn- und Verlustrechnung — 742 
$\S 278$ (aufgehoben) -750

VIERTER TITEL

(aufgehoben) -751

§§ 279-283 (aufgehoben) - 751

FÜNFTER TITEL

Anhang - 752

$\S 284$ Erläuterung der Bilanz und der Gewinn- und Verlustrechnung — 752

$\S 285$ Sonstige Pflichtangaben — 778

$\S 286$ Unterlassen von Angaben - 822

$\S 287$ (aufgehoben) - 831

$\S 288$ Größenabhängige Erleichterungen — 832

Sachregister -837 
